\title{
Conceptual User Interface Design Process for Healthcare App for Primary Care Level Services in India
}

\author{
Aratrika De", Woo Jeong Chon ${ }^{2, *}$ \\ ${ }^{1}$ U-Design, Inje University, Gimhae, South Korea \\ aratrika.de@gmail.com \\ ${ }^{2}$ Division of Multimedia, Inje University, Gimhae, South Korea \\ woojeong@inje.ac.kr \\ *Correspondence: woojeong@inje.ac.kr
}

Received: $6^{\text {th }}$ December 2018; Accepted: 28 ${ }^{\text {th }}$ December 2018; Published: $1^{\text {st }}$ January 2019

Abstract: Combining healthcare services on a primary care level, at a basic rather than specialised extent, for elementary treatment seeking people, can be challenging but yet useful. In fact, there are many different healthcare apps currently available in the emporium of India, however, their lack of usability as well as appropriate user interface is a major concern. Thus, the possibility of creating convenient and sustainable user interface and experience has great potentials in this regard. This paper presents a Proof-of-Concept (PoC) prototype for primary care level services in India, enabling seamless communication amongst pharmacies, clinics and relevant specialised services, demonstrating chronological steps of the conceptual user interface design process. The initial usability test results of the app reveal positive upshots. The PoC prototype, developed exploring service design processes, can be used for reference and guidance for the researchers, developers and other concerned stakeholders.

Keywords: Healthcare Apps; Primary Care in India; User Interface Design Process; Service Design

\section{Introduction}

Smartphone Apps have made a remarkable progress over the last few years. They are one of the most nascent objects used by people, globally. There are applications for various kinds of services like e-commerce, food tech, transport, healthcare et cetera bringing in convenience to daily lives. India's total population is 1,342,512,706 as recorded in 2018 [1] amongst which 299.24 million people are smartphone users [2]. The healthcare tech industry in India has seen a rapid growth in the recent years. An individual's healthcare can be taken care of with a tap on a mobile screen. With innovative and creative services coming to the market, from an on-call consultation to tele-medicines, they exist in various forms of services.

\subsection{Healthcare Services in Primary Care Level for Indians}

The primary care among masses is unpopular and is only used as a last resort because of unaffordability or any other compulsion [3]. Although some improvements have been made, the impression that the masses are rightly understaffed; poorly equipped and have poor infrastructure, 
including location. Besides, it is believed that a specialist in primary care will have the necessary knowledge to help counteract the real need-demand paradox in public health in India. The primary care specialist would be provided with the required training to conduct research in various sectors, which will determine and address the modifiable factors responsible for the low popularity and poor performance of primary health care, in addition to making an economic case for primary health care.

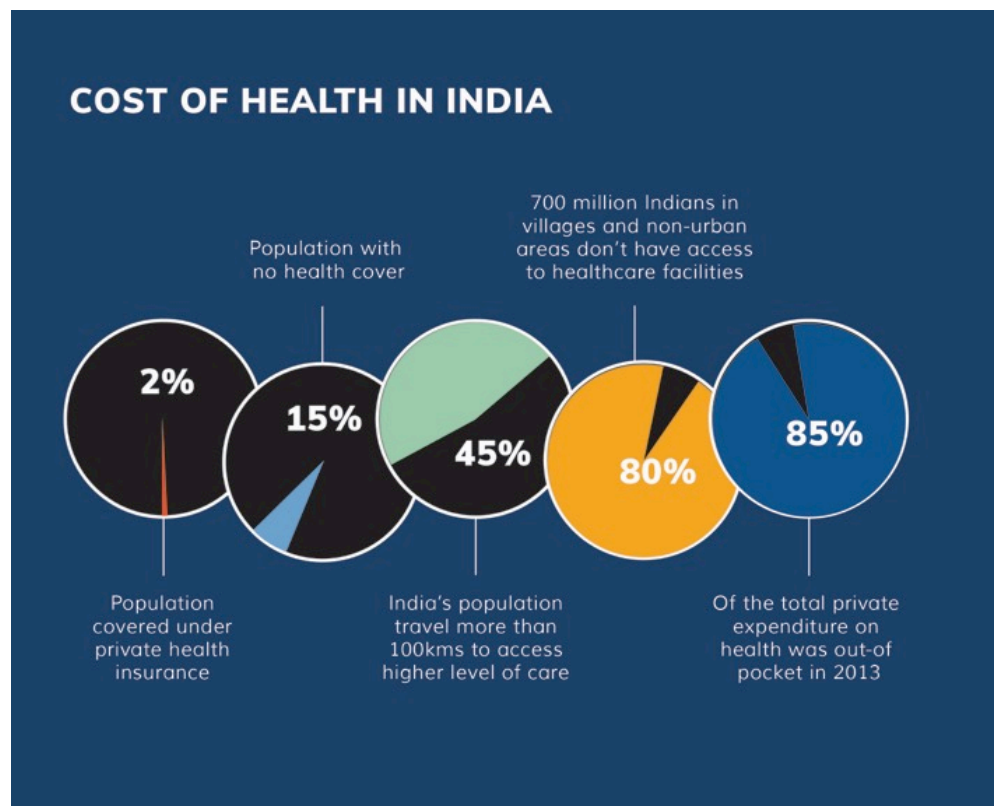

Figure 1. Cost of Health in India, adapted from [1].

When these issues are looked through the lens of a service design perspective, the existing structure deems to be in a dare need of convenience throughout the complete process. In the case of booking a clinic appointment for a general physician is applied and communicated over a while, the whole purpose of access for healthcare gets unjustified when one compares the outcome of the service seeker.

Now the health services like consultation, treatment and medical drugs - all of these services are available online [4]. There are various apps out there that are worth trying. The prominent ones are Practo, $1 \mathrm{mg}$, Medlife and Netmeds to name a few. Each of them serves a purpose and have a very successful and focused business model that has worked for them to be used and known in the Indian market. For example, Practo serves as a clinic directory, on the other hand, Netmeds provides the service to buy medicines off the app. If the concepts of the catalogue, pharmaceutical, other healthcare services at primary care level come together and offer it in one place, the efficiency of tasks performed increases as a result of the overall well-being of a potential user.

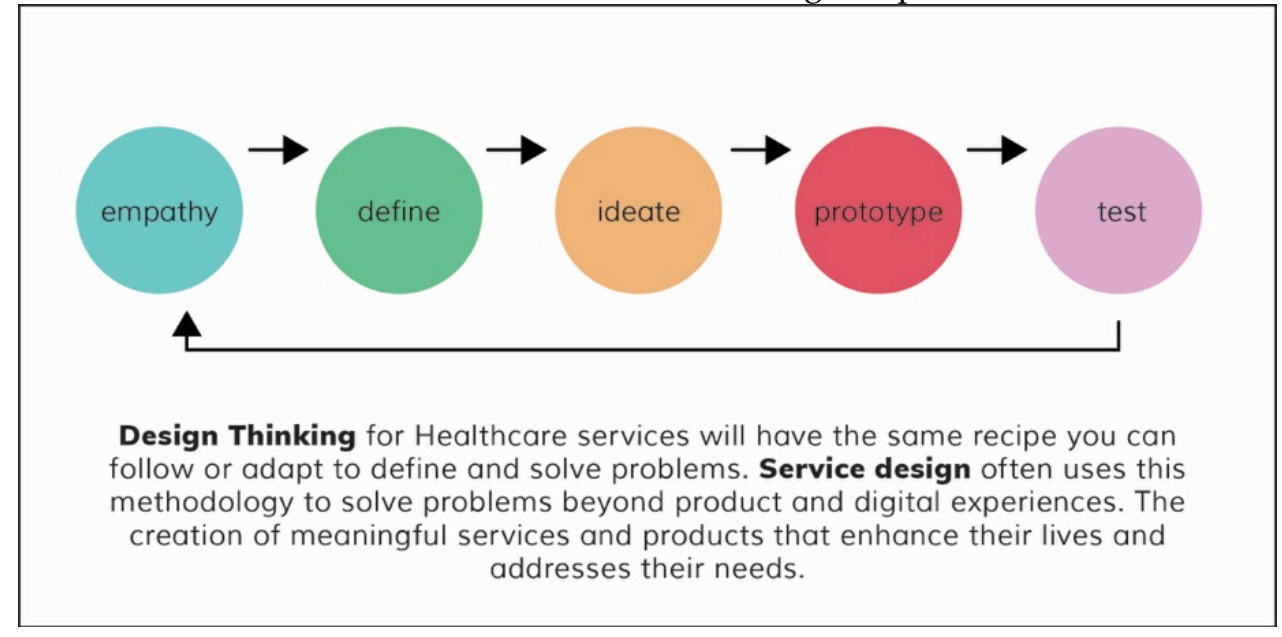

Figure 2. Design Thinking for Healthcare Service Design Process, adapted from [2]. 
Designers are responsible for building these infrastructures or platforms; such as maps that show the connections that are known as roads and signs between actors (such as stakeholders) that allow users to change their path. The traditional service specifications become a general 'infrastructure' which allows the community to access its own resources 'design in use'.

Companies want to provide customers with content and services as quickly and efficiently as possible, but the growing reluctance towards the perceived barrier poses a delivery barrier.

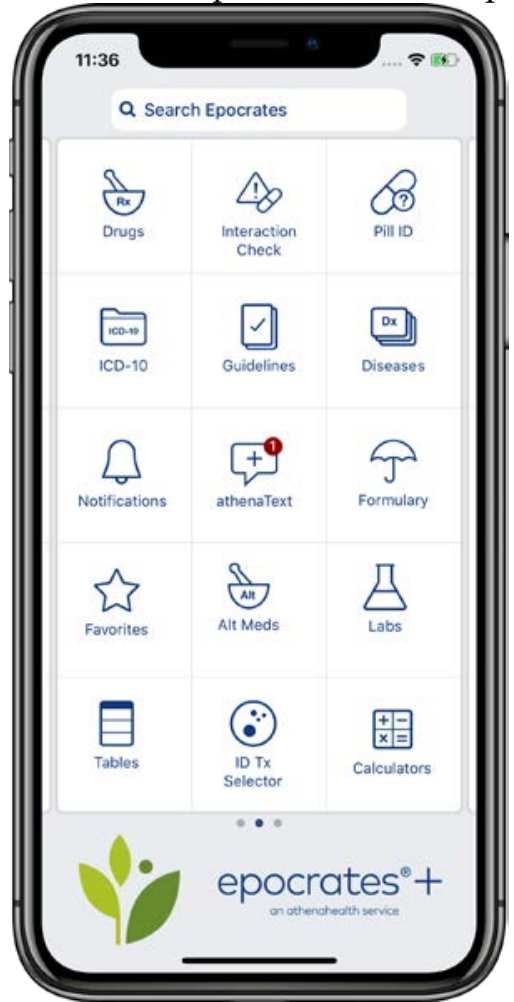

Figure 3. Visual content (services) of the Epocrates App

Table 1. SWOT Analysis of Epocrates App (Healthcare Service App)

\begin{tabular}{|c|c|c|c|}
\hline Strengths & Weaknesses & Opportunities & Threats \\
\hline Rated as high for ease of use & $\begin{array}{c}\text { Need to manage rapid } \\
\text { growth }\end{array}$ & $\begin{array}{c}\text { HiTech financial } \\
\text { incentives }\end{array}$ & $\begin{array}{c}\text { Competitors with more } \\
\text { resources and name } \\
\text { recognition }\end{array}$ \\
\hline $\begin{array}{c}\text { Lower costs compared to } \\
\text { competitors }\end{array}$ & Decreasing efficiency & $\begin{array}{c}\text { Need for data metrics to } \\
\text { define quality }\end{array}$ & New government regulations \\
\hline $\begin{array}{c}\text { Innovative culture of } \\
\text { healthcare service }\end{array}$ & $\begin{array}{c}\text { Increased leverage till last } \\
\text { year, weak profitability }\end{array}$ & $\begin{array}{c}\text { New payment models } \\
\text { motivate practitioners to } \\
\text { find efficient way to } \\
\text { collect revenue }\end{array}$ & Strong competitions \\
\hline
\end{tabular}

Table 1 presents the SWOT Analysis including threats and opportunities where the system may fail or may not be appropriate for all scenarios. There are threats from both the services of the service providers and the user community. In a pharmaceutical situation, threats such as peer intimidation, an understanding of the importance of service and its responsibilities for stakeholders and service providers, may exist - working group issues amongst students and learning skills of students. Chances of unhealthy competition and clashes between clinics and pharmacies may also exist. It could be overloaded for the primary care environment if one does not have the same reputation and performs well following the community standards. 


\section{Purpose \& Methodology}

The concepts of existing apps were studied and thematically analysed to learn the practised formats for mobile app user interface design. Understanding and creating UI design with the Use Case to reduce the steps to complete tasks using the Healthcare App. User-Centred Design was be applied to develop the UI Design Prototype using Android platform. Figure 4 demonstrates the steps in the design process and model.

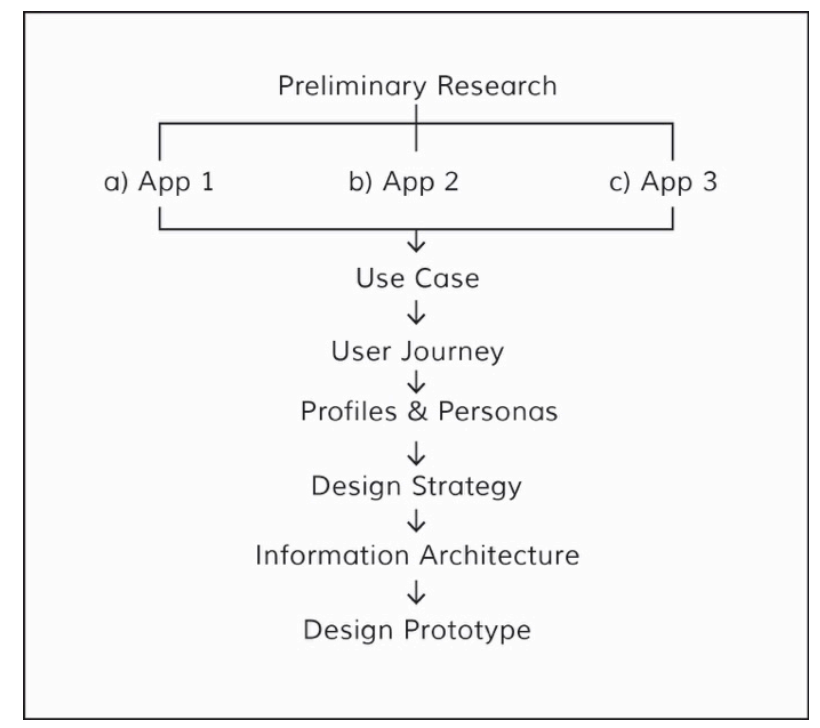

Figure 4. Design Process \& Method

\subsection{Recruitment of participants for the research}

For detailed usability test, healthcare app users in India was invited to participate in an online survey for data collection method to facilitate analysing people's experience, opinions, attitudes and perceptions [5]. They were recruited through proper online advertisement: flyers, information sheets, notices, internet postings and/or media were used to recruit subjects. The survey will be created on survey monkey, a survey generator tool on the web.

Questionnaire survey successfully attracted a total of 34 respondents. After accumulating and analysing the data, 7 of the respondent were excluded as they are not dependent on their smartphone apps in their daily lives. The age group and gender of the remainder respondent that fulfil the requirements were listed in table 2 .

Table 2. Respondent \% for the survey

\begin{tabular}{|c|c|c|c|}
\hline Age Group & Gender: F \%* & Gender: M\%* & Total \\
\hline $\mathbf{2 0 - 2 9}$ & $20 \%(4)$ & $10 \%(2)$ & $30 \%(6)$ \\
\hline $\mathbf{3 0 - 3 9}$ & $20 \%(4)$ & $40 \%(8)$ & $60 \%(12)$ \\
\hline $\mathbf{4 0 - 4 9}$ & $30 \%(6)$ & $30 \%(6)$ & $60 \%(12)$ \\
\hline $\mathbf{5 0 - 5 9}$ & $10 \%(2)$ & $10 \%(2)$ & $20 \%(4)$ \\
\hline
\end{tabular}

This questionnaire has received participation from a big range of respondent in terms of age group. Among the 7 remainder respondent, 34 respondents are from the age group of 20-59 and the male respondents were $5 \%$ more than females for this survey as observed from the Table 2 . They are a mixed group of people who are healthcare app users in India.

\subsection{User Preference Analysed}

As shown in Figure 5, the participants were asked about their preferred service amongst: the options of Tele-Booking of clinic appointments, On-call general physician consultation, Pharmacy delivery and Directory (yellow page) of clinics and medical facilities. The most popular preferred 
services were suggestive of home call services like On-call general physician and pharmacy home delivery equally upto $60 \%$. The option for directory information did not seem as a very important choice for any of the participants.

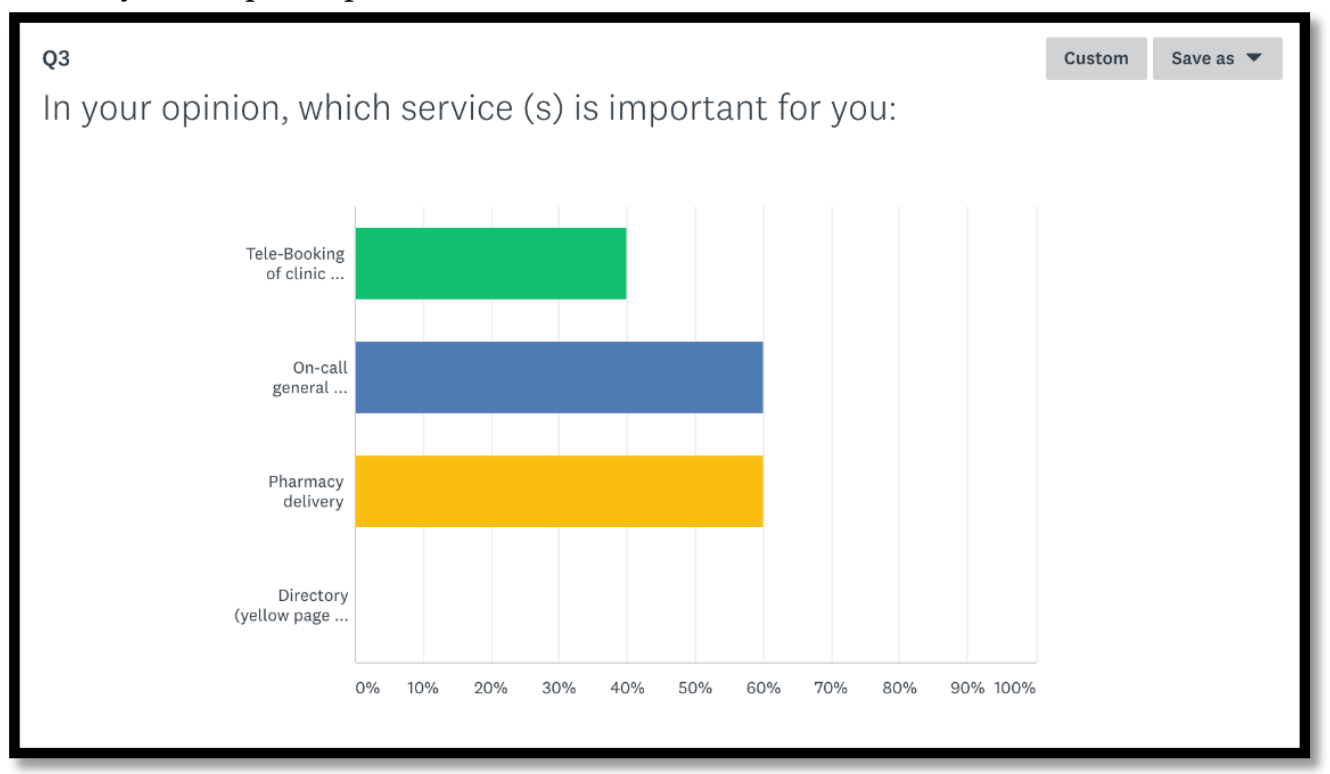

Figure 5. Users' feedback on preferred service

The experience of a healthcare culture of a certain place can be understood through a visit at the hospital or clinic for an appointment in person. People are turning to the Internet to find doctors. Many websites, filled with reviews and ratings, are helping people make a more informed choice about how to seek out healthcare and giving patients-both disgruntled and satisfied-a place to air out their opinions. Given a health emergency situation a patient would want to minimize their discomfort by not waiting long time for their turn to come. The question in the survey in Figure 6, shows that $60 \%$ of the participants have waited at least $0-1$ hour at the hospital or clinic, and $40 \%$ of them have waited for 2-4 hours.

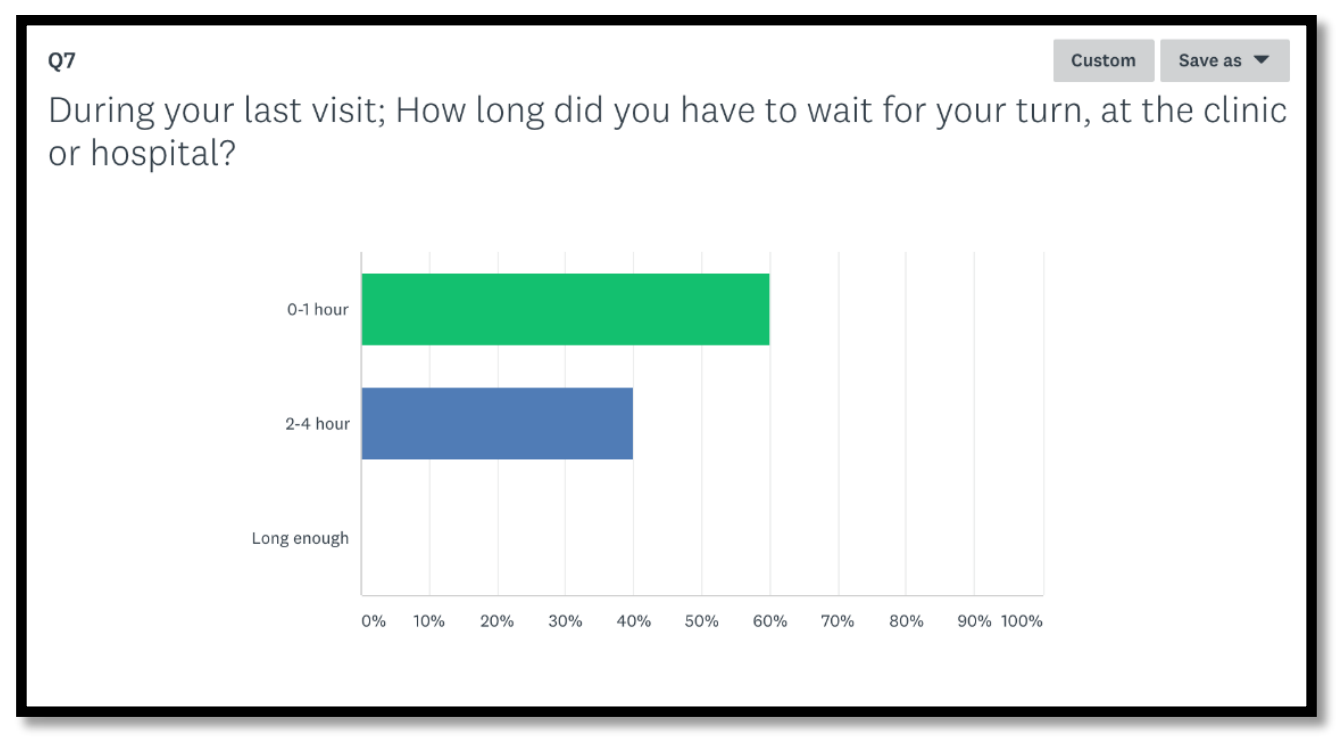

Figure 6. Duration of waiting time for appointments

Pharmacy delivery as a service can ease a lot of inconvenience in an Indian scenario of Healthcare service. A typical order of a list of drugs prescribed by the physician can take a while to get and start the medication. A number of factors are hurdles and challenges if this were to be a focus of the discussion, for example: a patient while being sick finds it very inconvenient to go and wait in the queue for a long time till their turns come. Another scenario, where there are options for home delivery, in many such cases the local pharmacists can only find time to deliver at the end of 
the day. However, the figure 7 shows the poll of the question, "Under what circumstances will you require for medicines to be delivered from a pharmacy?".

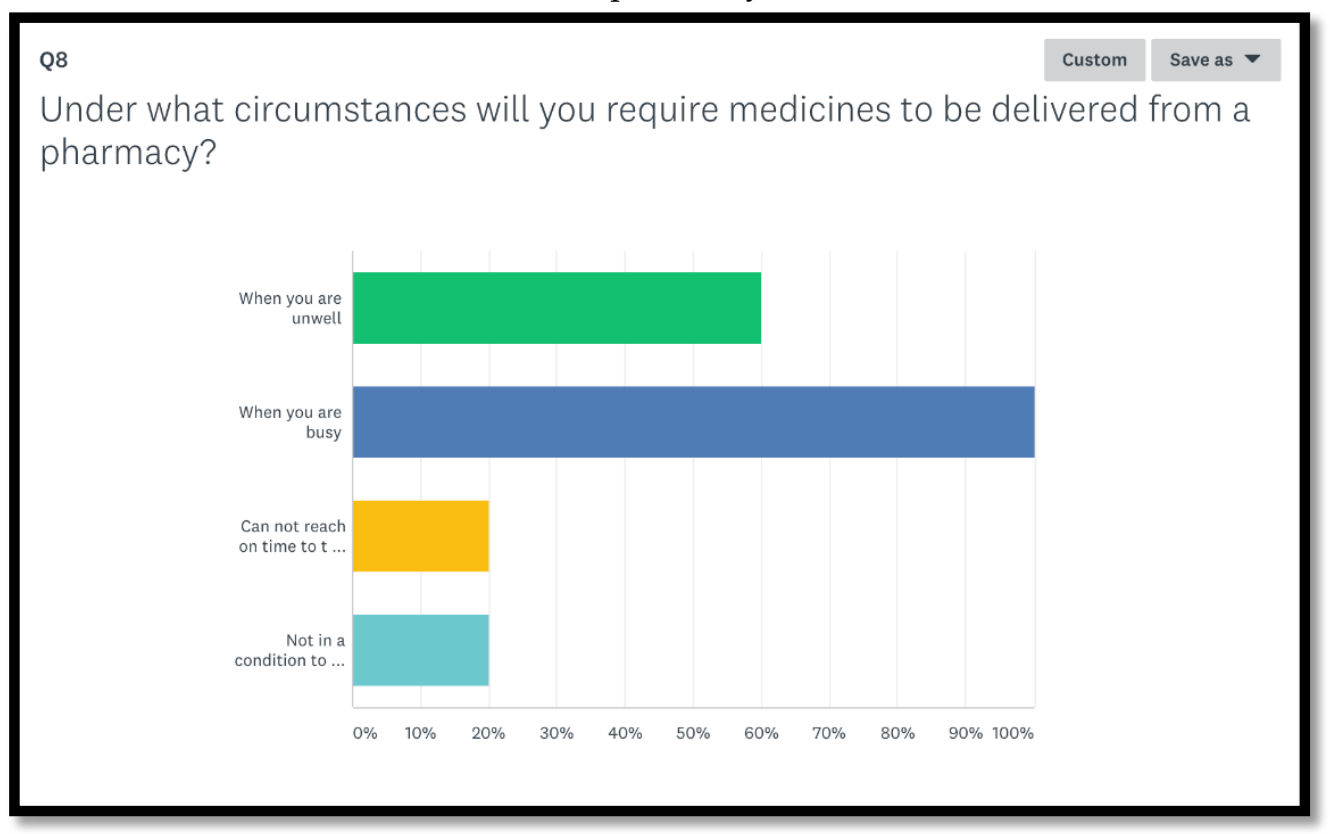

Figure 7. Circumstance when home delivery is preferred

As it is seen, $100 \%$ of the participant selected the option, "When they are busy", this does make a lot of sense of not having the bandwidth to collectively complete the healthcare check-up, pick up prescription and get tested in the order as expected. $60 \%$ of the participant selected "When they are sick/unwell", they will need a home delivery from the pharmacy. There are services that know picking up the prescriptions can be a hassle, especially when patients and customers need them right away, so the healthcare or pharmacy services happy to offer convenient prescription delivery services for medications, over-the-counter products, and medical supplies to the home or office.

The participant's initial thoughts put into answering these questions are the results providing information that will be considered for the content prioritisation and focus on the design process of the app.

\section{Design Strategy \& Conceptual Model}

Getting the full benefit from a well-designed healthcare service app means not just understanding User Experience (UX), but also getting a solid grasp on what makes the healthcare web experience different [6].

Healthcare apps offer complex, life changing services that play a different role in consumer lives than say, self-service organizing one's own healthcare.

\subsection{Scenario \& Task Analysis}

Scenarios describe the stories and context behind why a specific user or user group comes to use a website or mobile app. They note the goals and questions to be achieved and sometimes define the possibilities of how the user(s) can achieve them on the site. Scenarios are critical both for designing an interface and for usability testing [7].

These stories have details about the user's decisions and how they behave professionally and personally. Figure $8,9 \& 10$ are examples used in the process of user scenario.

Scenarios are further broken down into tasks that cover the user's functions. Scenarios cover a slice of the range of tasks. Tasks and how they fit together are the user's Mental Model that includes the nature of the task, how they are trying to accomplish it and its importance.

The tasks can have a prevalent flow or some have sequential dependencies within tasks. Through the tasks, the designer can see the mistakes made by users and improve the flow. 


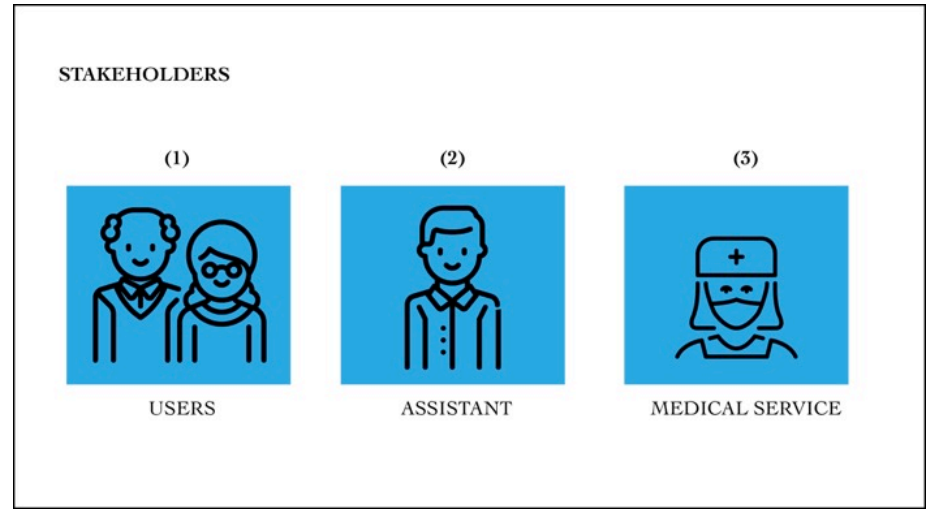

Figure 8. Stakeholders of the Scenarios: (1) User, (2) Assistant, (3) Service Provider

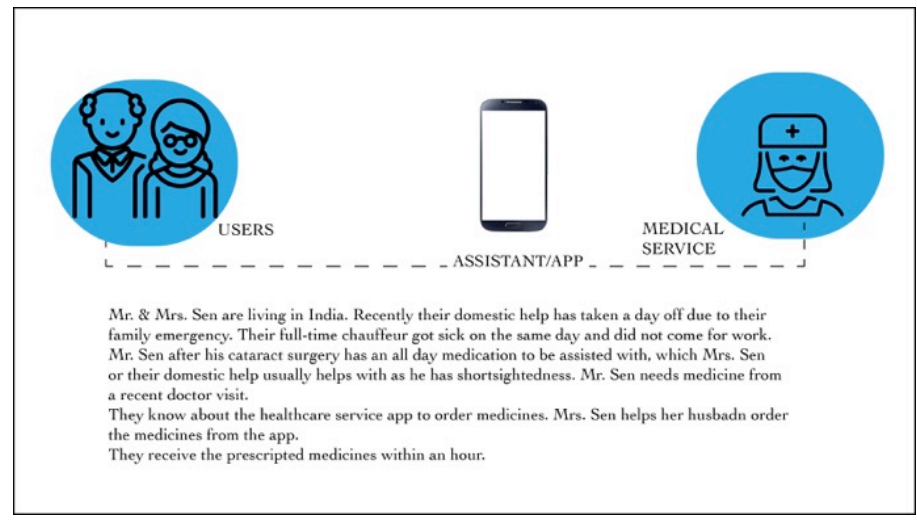

Figure 9. User Scenario of Healthcare App

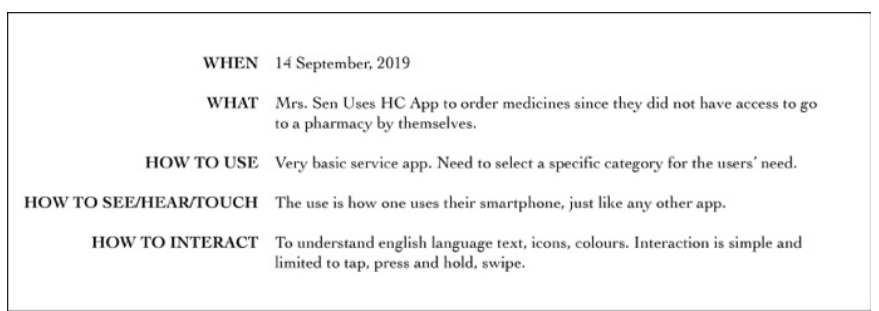

Figure 10. Questions generated by the user scenario: seeking the service

Task flow design is iterative. Flow moves from high-level tasks, through steps for those tasks, and finally to the level of the page flow or screen flow.

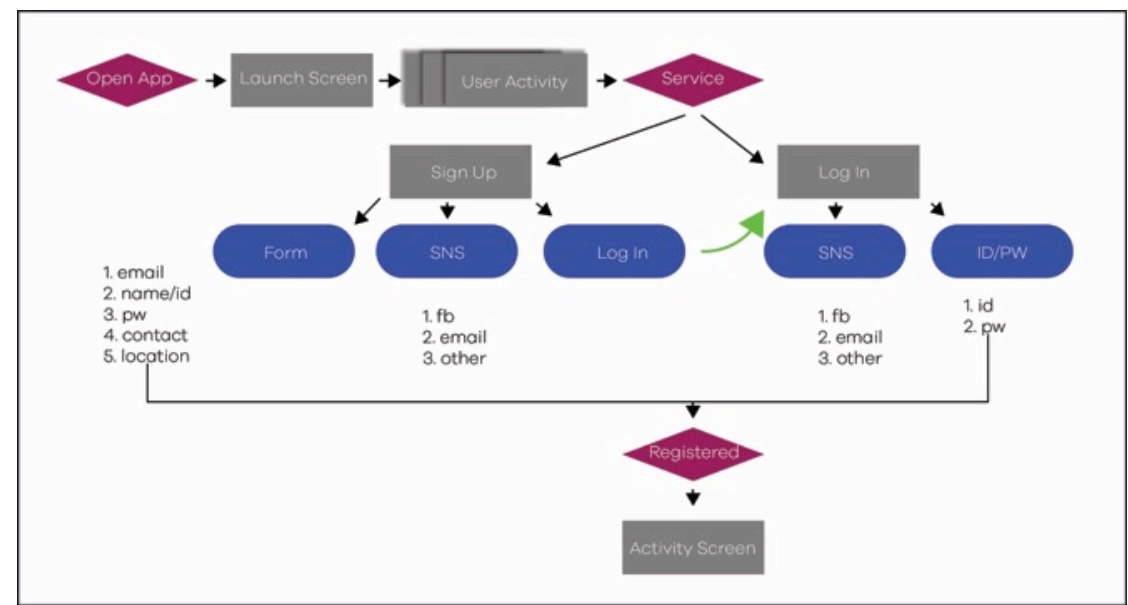

Figure 11. Task Flow for User Conversion: Sign Up \& Log In 


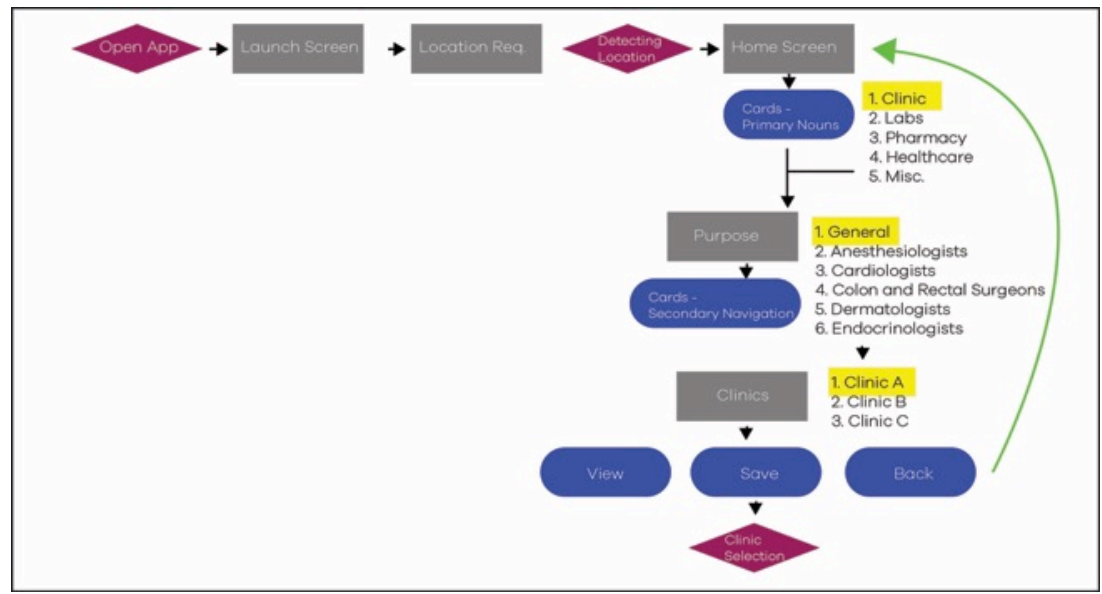

Figure 12. Task Flow for Clinic Search

The above images presented in Fig. $11 \& 12$ show the tasks the user needs to perform to reach completion of their desired service.

Table 3 helps to identify tasks to analyse and redesign, based on target stakeholders. In this case of service the potential stakeholders are the users i.e. the consumers, the medical representative like a general physician or a pharmacist, a customer service representative and the single point of contact (SPOC).

Table 3. Format Guide To Identify Tasks and Redesign

\begin{tabular}{|c|c|c|c|c|}
\hline & CSR & SPOC & User & Healthcare Rep. \\
\hline Enter Location & & & $\mathrm{X}$ & $\mathrm{x}$ \\
\hline Receive Location & $x$ & $x$ & & $X$ \\
\hline View Primary Categories & & & $x$ & \\
\hline Select from Primary Categories & & & $x$ & \\
\hline View P.C. Option Info. Cards & & & $x$ & \\
\hline Select Info cards for booking service & & & $x$ & \\
\hline Review Booking & & $x$ & & $x$ \\
\hline View sign Up/log in & & & $x$ & \\
\hline Enter info for sign up/log in & & & $x$ & \\
\hline Send Follow up link & & $\mathrm{X}$ & & \\
\hline Select for booking & & & $x$ & \\
\hline Receive confirmation for booking & $\mathrm{x}$ & & $x$ & $x$ \\
\hline View Upload prescription screen & & & $x$ & \\
\hline Upload Prescription & $x$ & $x$ & $x$ & $X$ \\
\hline View Prescription & $x$ & $x$ & & $x$ \\
\hline Review Prescription & & $X$ & $x$ & $X$ \\
\hline Confirm Order & & $x$ & $x$ & $x$ \\
\hline Cancel Order & & $x$ & $x$ & $X$ \\
\hline Forgot ID/ PW & $x$ & $x$ & $x$ & \\
\hline Assistance for ID/PW & $x$ & $x$ & $x$ & \\
\hline Grievances & $x$ & $x$ & & \\
\hline FAQs & $X$ & $\mathrm{X}$ & & $X$ \\
\hline
\end{tabular}

From the above table, the roles of stakeholders like the single point of contact (SPOC) and the user have more tasks compared to the healthcare representative and customer service representative (CSR). These are perceptual and based on market segments.

After observation from the Table Maps, as above, this can be taken to a step forward and get a visual understanding of the importance and frequency of the tasks. 
Factors must be learnt during this step of the Analysis Phase:

- Conditions: Required tools for the product are wireless internet - wifi, smartphone, knowledge and experience using the smartphone and the internet together.

- Performance Measure: It must be performed with ease, as it is used to bring convenience to the user.

- Frequency: The user should ideally make use of it three to four times a month, as this app will be in their phones.

- Difficulty: If this has to be graded on a scale of one to five, (five being the hardest) the level of difficulty should not be higher than two to three.

- Importance: This app is a one-stop solution for primary care services. The user can consider this as an important app to use on almost regular bases.

- uSteps: Logical steps for performing the task - Download the app, detect the location, browse options for the user's desired services, book the service, use the service.

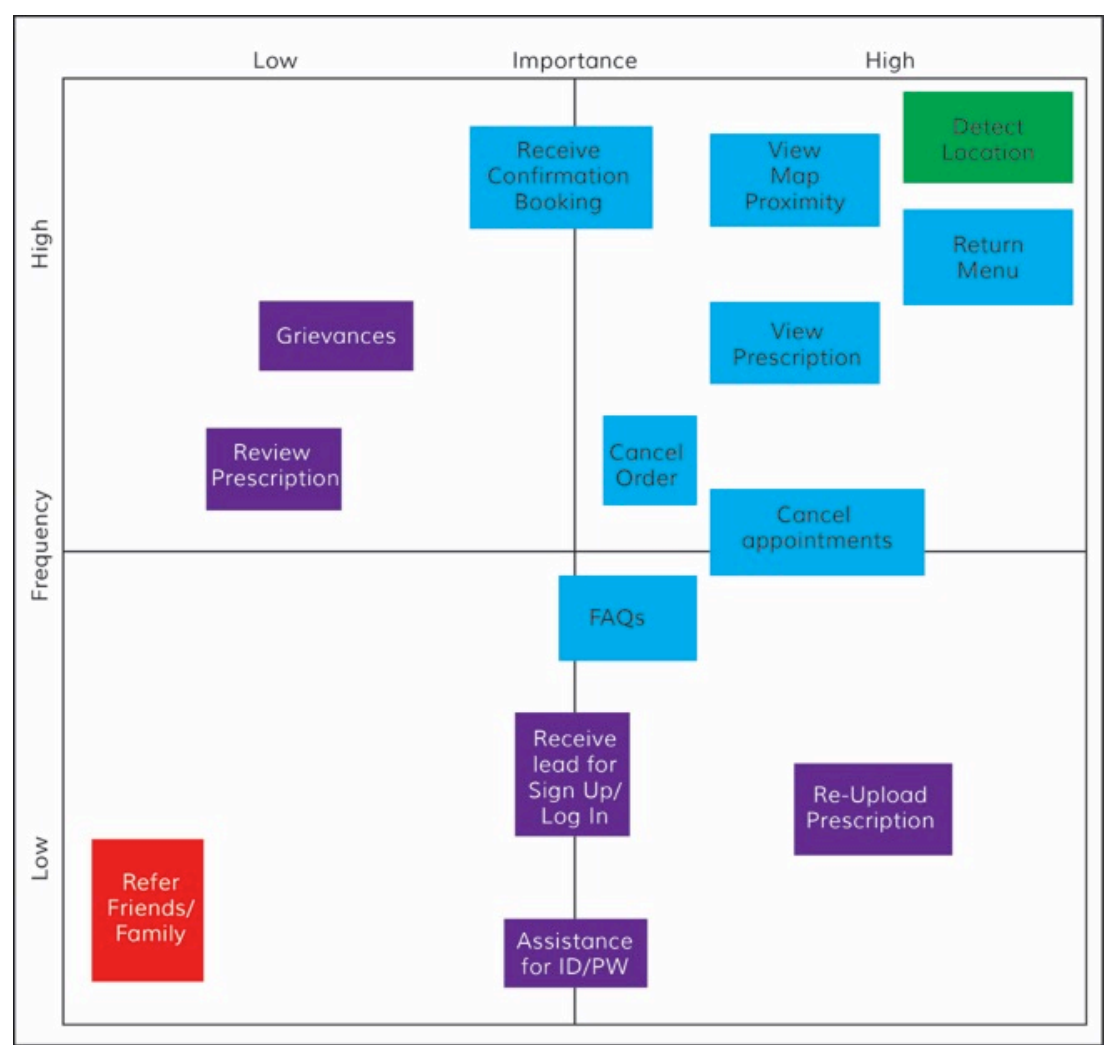

Figure 13. Frequency and Importance of Diagram of Tasks

The colour-coded boxes in Figure 13 represent the frequency and importance of the task analysis portion of this process as follows:

- Green: The most frequent and important part of the task- to detect and read the location. Identifying the location can only further provide information about the service, which is the sole purpose of the product.

- Blue: The second most important and frequent tasks like Viewing of Map Proximity and Returning to the menu, cancelling appointments. Giving the user the flexibility to change their minds highlights the empathy factor and gives it a more organic approach to the complete flow.

- Purple: It is an area of doubt for the importance and frequency, but at the same time, crucial tasks. For example, Grievances can be used after a certain point, when the app starts to grow and gain fair popularity. So this zone will depend on the next steps of the design process.

- Red: Least important and infrequent task. Referring, outreach to more users through friends, is early in the phase to explore. 
The analysis from the map diagram defines the goal of the analysis, which leads to Navigation Design after identifying relationships and problems. This can be taken forward to a focused direction and eliminate tasks to create the information architecture. Any system designed for people to use should be easy to learn, remember and be useful, that is, contain functions people really need in their work and be easy and pleasant to use [8].

\subsection{Information Architecture}

Information architecture is a foundation of efficient user experience [9]. The information architecture is like a layout blueprint that must be generated by a visual arrangement such as a wireframe. It is a core stage before IA creation to define product objectives.

- The initial phase for IA is deciding of the primary nouns, primary noun attributes and navigation flow.

- Primary Nouns: PN is vital in segregating the main tasks when the PN is obvious it helps the user visualise the purpose and scope of the app. For example, for the Healthcare Service: the user will initially share location to detect the main services (PN) available in that area. They can decide with the cues what to do with the options given to them.

- Primary Noun Attributes: PN has attributes. These attributes appear from their PN group. When users select their desired healthcare service, they can view the options for the selected service. The possibilities are the Primary Noun Attributes (PNA).

- Navigation Flow: If a view equals PN/ Healthcare Service, then action will take the user from one view/screen to another. That transition is navigation flow. If the user wants to select a service, the action of selection's response is the flow of the navigation.

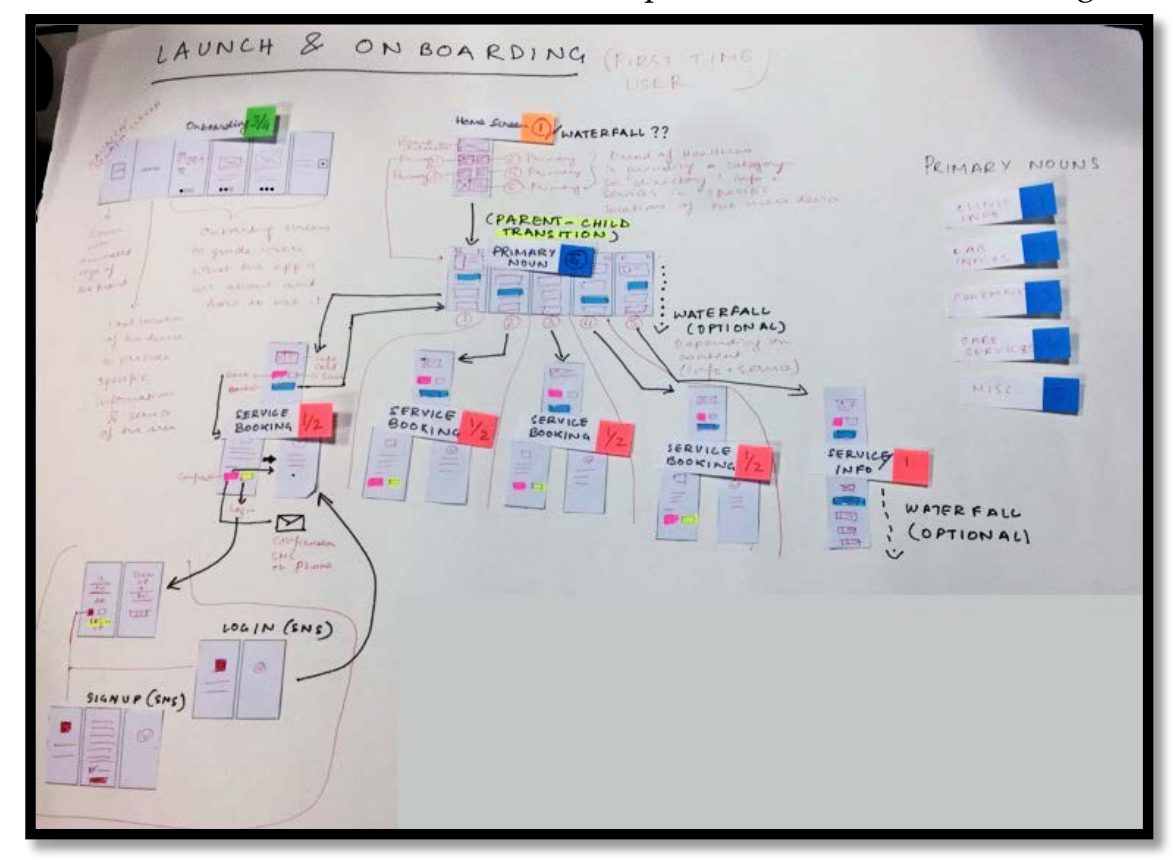

Figure 14. Rough Primary Noun, Attributes \& Navigation Flow

To understand the information architecture a rough structuring of the flow of the tasks, as shown in Figure 14, puts together the understanding of the nouns and attributes, This also assists in reducing or increasing the tasks, as shown in Figure 15, for unnecessary repetition or steps that are not making sense in the process.

The Value of IA in the design process is the realisation of the contents that will be in the interface. Hence, all the information has to be organised and grouped for all nouns and attributes. It prepares for assigning the navigational scheme at each level.

Value for the end users: increases efficiency and focuses on high priority content. 


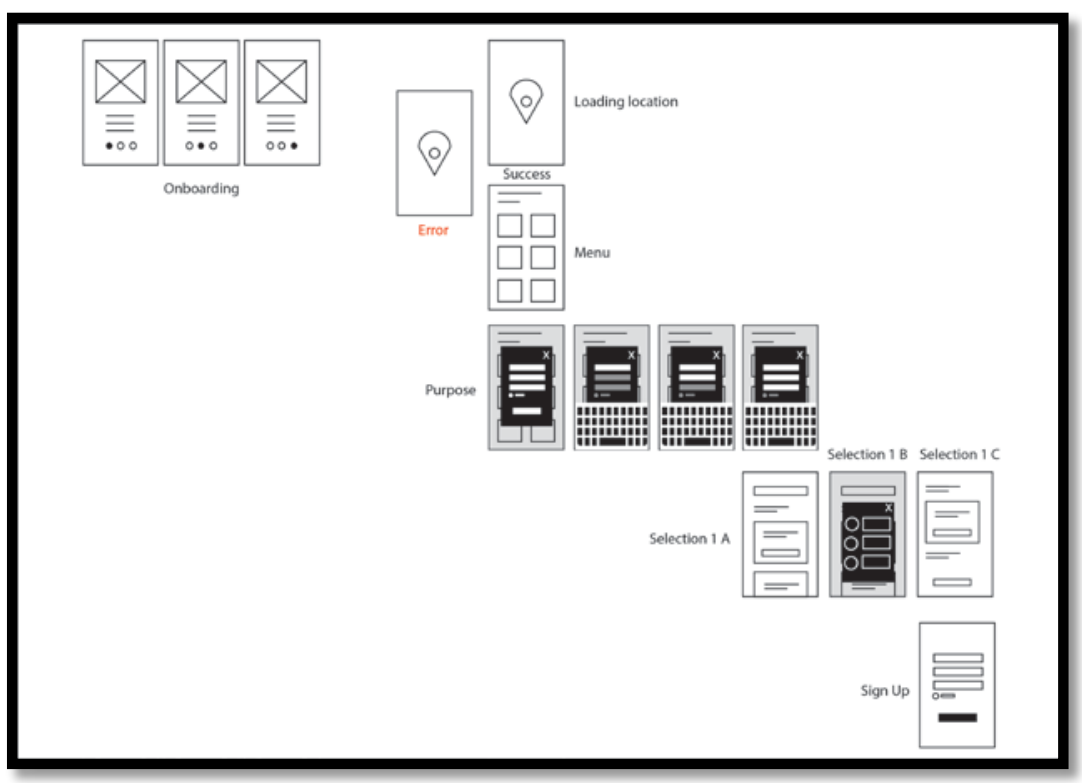

Figure 15. Navigation Flow Draft

This table of IA (table 4) shows the frequent, critical information that supports the strategy of the healthcare service design to the top.

Table 4. Navigation Contents with Information Architecture

\begin{tabular}{|lllll|}
\hline Clinic & Pharmacy & Med. Services & Fitness & Misc. \\
\hline Clinic 1 & Pharmacy 1 & A & A & A \\
\hline Scroll down & Scroll down & Scroll down & Scroll down & Scroll down \\
\hline Clinic 2 & Pharmacy 2 & B & B & B \\
\hline Scroll down & Scroll down & Scroll down & Scroll down & Scroll down \\
\hline Clinic 3 & Pharmacy 2 & C & C & C \\
\hline
\end{tabular}

\subsection{Getting Ready for Design Prototype}

Understanding the potential of recognised and unique specialised services for convenience in the field of HC, adds value to the user experience design and the well - being of the community.

Preparing the prototype is an essential step for the design process, as this version will be taken for user testing for the final User Interface Design. Some factors are followed to bring in the visual aspect of the design; they are the colour, typography, layout, navigation and the transition to name a few.

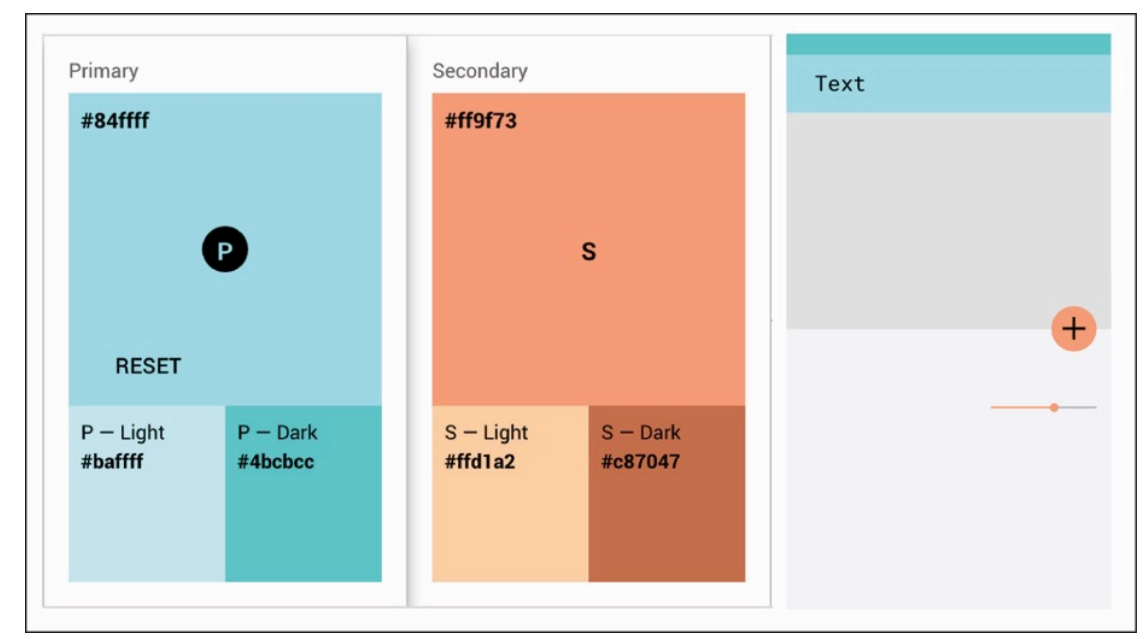

Figure 16. Colour Scheme for the Healthcare Service App Prototype: Cyan and Rust [10]. 
- Colour: The app's primary and secondary colours and their variants help create a colour theme that is harmonious, ensures accessible text, and distinguishes UI elements and surfaces from one another. The selected colour scheme is a tone of cyan as primary colour and rust as the secondary colour, as shown in figure 16. The cyan is picked with the theme of healthcare in mind, and the tone of rust is selected for the location relevant factor, the Indian flag colour has saffron so it would be somewhat in a familiar palette.

- Typoraphy: Typography is important. Choosing the right typography can give any website or mobile app a sense of sharpness and polishing. On the other hand, lousy typography choices distract and tend to attract attention. Making typography readable, easy to understand and readable is essential. Table 5 demonstrates example of typography used for the prototype.

Table 5. Sample Typography for the Healthcare Service App Prototype, adapted from [11].

\begin{tabular}{|c|c|c|c|}
\hline Preview & Font & Style & Size \\
\hline H2 & Roboto & Regular & 16 \\
\hline BUTTON 1 & Roboto & Regular & 14 \\
\hline BUTTON 2 & Roboto & Regular & 14 \\
\hline Instruction 1 & Roboto & Regular & 12 \\
\hline Instruction 2 & Roboto & Regular & 10 \\
\hline Instruction 3 & Roboto & Italic & 9 \\
\hline
\end{tabular}

- Layout: A layout, as demonstrated in figure 17, defines the structure of the user interface [12], such as an activity, in an app. All the elements in the layout are constructed using the view and viewgroup objects hierarchy. A view generally draws something with which the user can see and interact.

- Navigation: Navigation, as shown in figures 18 and 19, is the cue that takes users to where they want to go. It helps users to find the information they are looking for from an app or website. Navigations are most often seen as a bar at the top of the page with text links, among other examples.

\section{Conclusion}

Keeping the cultural aspect of a country like India with diversities in each metropolitan city, reaching out to the users through technology and smartphone service apps is a motivating factor for this research and design initiative. The complete design concept was clinched by examining various existing healthcare apps and their challenges. This has thus assisted in structuring the layout of the app and deriving the successive steps along with visual process of scenarios, information architecture and integrating all these aspects together.

Due to widespread adoption of technology, mobile or internet based healthcare service is observing enormous growth - thus demand high attentions from the stakeholders including the researchers and the developers. Having many available platforms, there is an opportunity to fulfil this need and bring benefit to the target user groups. Creating a usable system to track and aid to the parents' care needs can bridge the gap. Our research presents a PoC - convenient services can be availed through this prototype developed for Android-operated smartphones. The users can book services for care in various forms and track medical records. The opportunity to explore the usability and design aspect of healthcare apps will contribute to both industries and actual processes of collaboration.

Future research plan includes conducting detailed usability tests, expanding the prototype for other platforms such as iPhones. Integrating various other relevant services to provide seamless healthcare is going to be remain as the main focus of this research. 


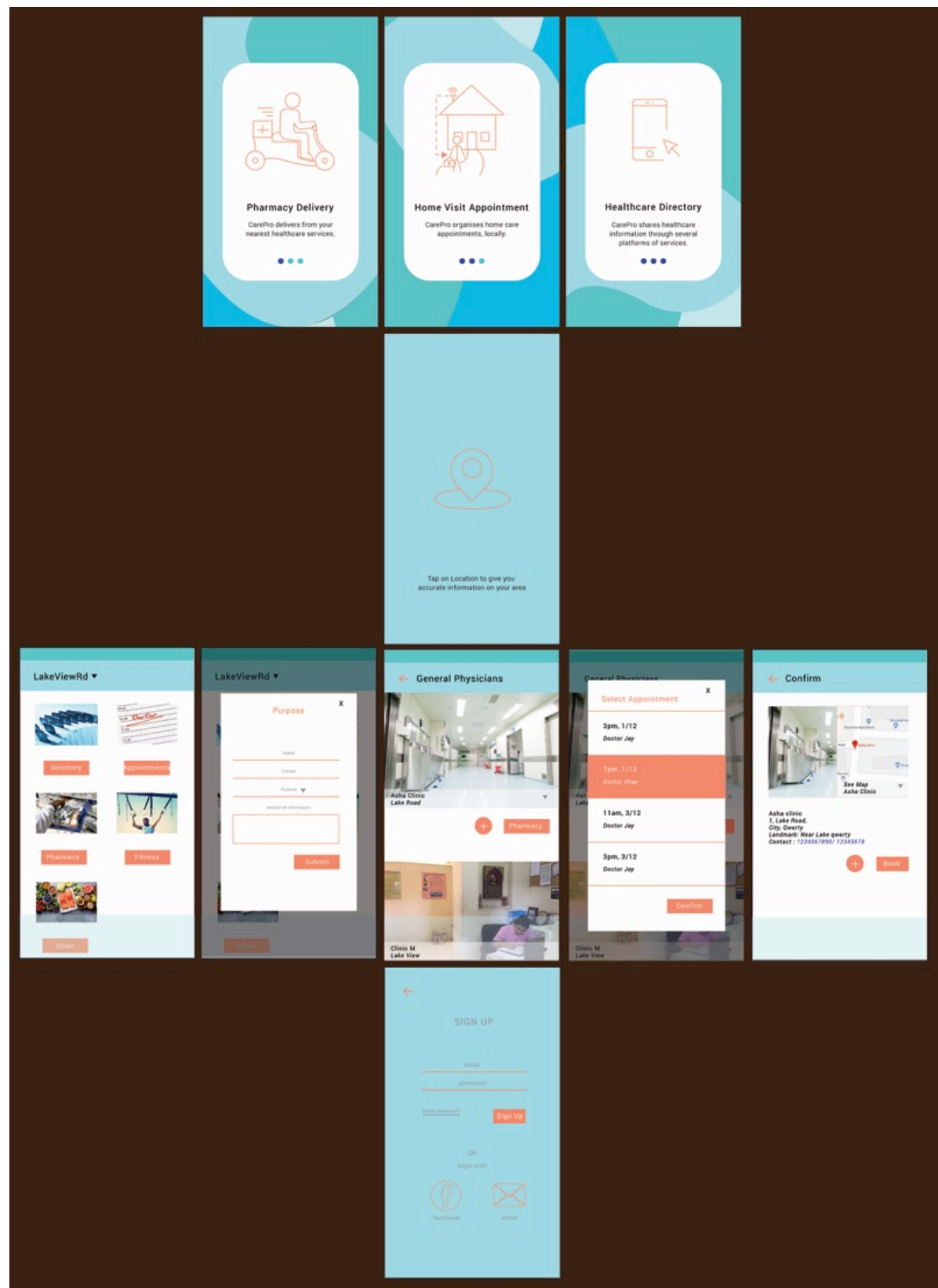

Figure 17. Prototype User Interface Layout of the Healthcare Service Application

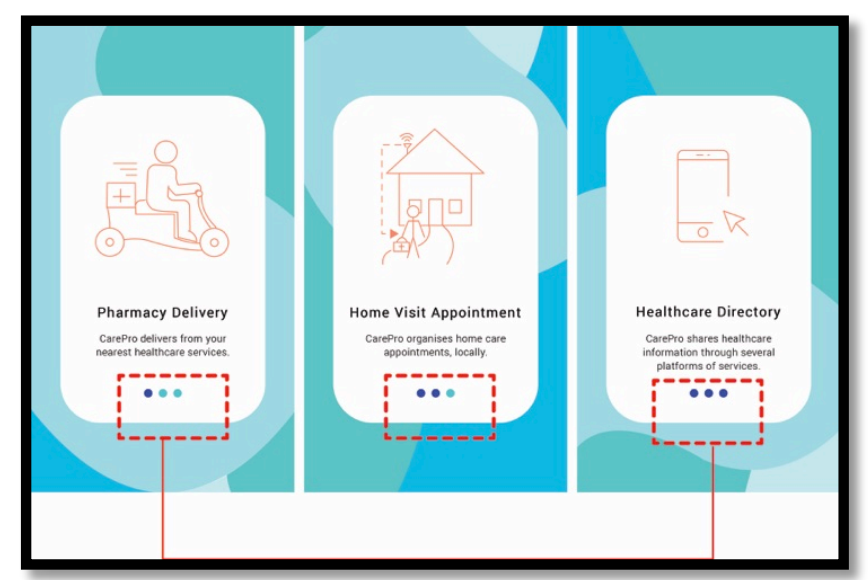

Figure 18. A cue given through colour, highlighting navigation is indicating user to swipe. 


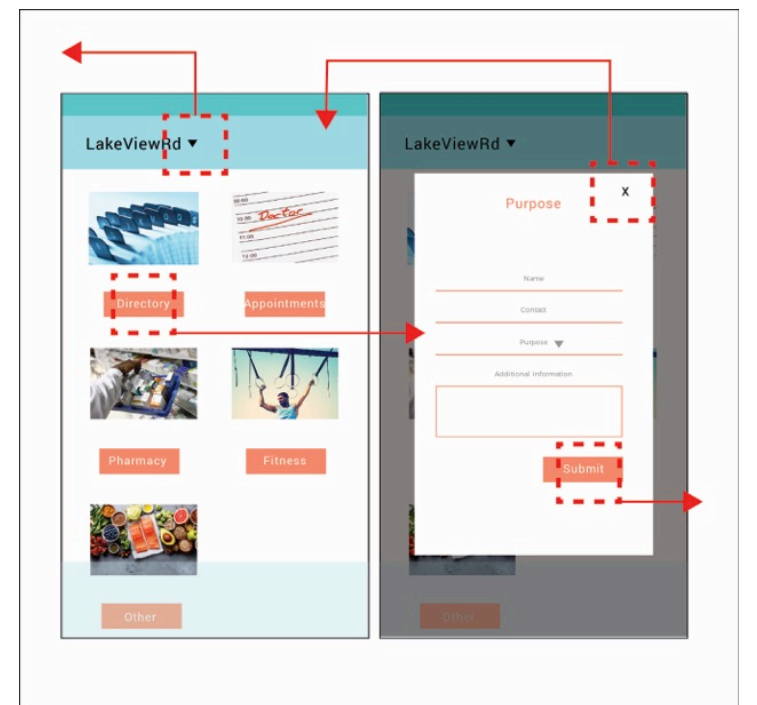

Figure 19. Cues are provided through icons, buttons and text for navigation flow

\section{References}

[1] Health Analytics India (2015), “Growing burden of healthcare costs”. dataLEADS. Available: http://healthanalyticsindia.com/health/growing-burden-of-healthcare-costs.html.

[2] Amanda Makulec (2014). “Design thinking \& global health: an opportunity”, The Pump, 5th August 2014. Available: https://thepump.jsi.com/design-thinking-global-health-an-opportunity.

[3] Faizi N, Khalique N, Ahmad A, Shah MS (2016). “The dire need for primary care specialization in India: Concerns and challenges” in Journal of Family Medicine \& Primary Care, 5 (2), pp. 228-233, 18th October 2016. Available: http://www.jfmpc.com/text.asp?2016/5/2/228/192382.

[4] Payal Joshi (2018). “5 Best Healthcare Apps for Android in India”, 3nions, 21st August 2018. Available: https://www.3nions.com/5-best-healthcare-apps-for-android-in-india/.

[5] Coskun, A., Kaner, G., \& Bostan, I. (2017). "Is Smart Home a Necessity or a Fantasy for the Mainstream User? A Study on Users' Expectations of Smart Household Appliances”, in International Journal of Design, 12(1), pp. 7-20, April 2018.

[6] Eric Martin (2018). “Healthcare Website Design Strategy”, Influence Health, 14 October 2018. Available: www.influencehealth.com/blog/user-experience-is-more-than-good-design\%e2\%80\%a6especially-in-healthcare.

[7] U.S. Dept. of Health and Human Services (2006). The Research-Based Web Design \& Usability Guidelines, Enlarged/Expanded edition. Washington: U.S. Government Printing Office, 2006. Available: https://www.usability.gov/how-to-and-tools/methods/scenarios.html.

[8] Gould, J. D., \& Lewis, C. (1985). Designing for usability: Key principles and what designers think. Communications of the ACM, 28(3), 300-311.

[9] Nick Babish (2017). A Beginner's Guide to Information Architecture for UX Designers, Adobe Blog, 20 November 2017. Available: https://theblog.adobe.com/a-beginners-guide-to-information-architecture-for-ux-designers.

[10] Material Design (2018). “Tools: Use Material tools to simplify your workflow”. Available: https://material.io/tools.

[11] Material Design (2018). “Understanding typography”. Available: https://material.io/design/typograp hy/understanding-typography.html\#

[12] Android Library (2018). Available: https://developer.android.com/reference.

(C) 2019 by the author(s). Published by Annals of Emerging Technologies in Computing (AETiC), under the terms and conditions of the Creative Commons Attribution (CC BY) license which can be accessed at http://creativecommons.org/licenses/by/4.0. 